\title{
Fabrication and Optimization of Linear PEI- Modified Crystal Nanocellulose as an Efficient Non-Viral Vector for In-Vitro Gene Delivery
}

\author{
Haghighat Vakilian ${ }^{1}$, Eduardo Andres Rojas², Lida Habibi Rezaei ${ }^{3}$, \\ Mehrdad Behmanesh ${ }^{* 1,4}$
}

\begin{abstract}
Background: One of the major challenges in gene therapy is producing gene carriers that possess high transfection efficiency and low cytotoxicity (1). To achieve this purpose, crystal nanocellulose (CNC) -based nanoparticles grafted with polyethylenimine (PEI) have been developed as an alternative to traditional viral vectors to eliminate potential toxicity and immunogenicity.

Methods: In this study, CNC-PEI10kDa (CNCP) nanoparticles were synthetized and their transfection efficiency was evaluated and compared with linear cationic PEI10kDa (PEI) polymer in HEK293T (HEK) cells. Synthetized nanoparticles were characterized with AFM, FTIR, DLS, and gel retardation assays. In-vitro gene delivery efficiency by nano-complexes and their effects on cell viability were determined with fluorescent microscopy and flow cytometry.

Results: Prepared CNC was oxidized with sodium periodate and its surface cationized with linear PEI. The new CNCP nano-complex showed different transfection efficiencies at different nanoparticle/plasmid ratios, which were greater than those of PEI polymer. CNPC and Lipofectamine were similar in their transfection efficiencies and effect on cell viability after transfection.

Conclusions: CNCP nanoparticles are appropriate candidates for gene delivery. This result highlights CNC as an attractive biomaterial and demonstrates how its different cationized forms may be applied in designing gene delivery systems.
\end{abstract}

Keywords: Crystal Nanocellulose, Gene transfection, Nanoparticle, Nano-complex.

\section{Introduction}

Only about $7 \%$ of human diseases are treatable with the estimated 10,000 drugs available on the market (2). While a large portion of available drugs offers temporary relief from disease-related symptoms, gene therapy provides long-lasting therapeutic protein production in patients by delivering functional genes (3). The potential becomes more interesting when considering that $80 \%$ of human diseases are associated with dysfunctional genes. However, safe and efficient gene therapy techniques are in the developmental stage. Whatever the target gene, it should be cloned and loaded on a proper vehicle to be expressed and encounter the disorder at its source. Viral vector-based systems such as retroviruses, adenoviruses, and adeno-associated viruses have demonstrated superior transfection efficiencies and have been widely studied for gene delivery purposes $(4,5)$. Despite significant successes, the life-threatening potential of viral

1: Nano biotechnology Department, Faculty of Bioscience, Tarbiat Modares University, Tehran, Iran.

2: Department of Pathology and Molecular Medicine, McMaster Immunology Research Centre, McMaster University, Hamilton, ON, Canada.

3: Department of Stem Cells and Developmental Biology, Cell Science Research Center, Royan Institute for Stem Cell Biology and Technology, ACECR, Tehran, Iran.

4: Department of Genetics, Faculty of Biological Sciences, Tarbiat Modares University, Tehran, Iran.

*Corresponding author: Mehrdad Behmanesh; Tel: +98 21 82884451; E-mail: behmanesh@modares.ac.ir.

Received: 2 Sep, 2019; Accepted: 10 Sep, 2019 
vectors is a limiting factor. These systems may cause important safety issues including immunogenicity and carcinogenicity, and they have high setup costs. Consequently, non-viral vectors have received considerable attention due to their safety, stability, and cost-effectiveness. However, gene therapy researchers aim at refining them in some aspects including toxicity and transfection rate $(6,7)$. In the pursuit of this approach, cellulose, an abundant and biodegradable biomaterial, has been an attractive source used in gene delivery systems (8). Among various derivatives that have been used for this purpose, including hydroxyethyl cellulose (HEC), hydroxypropyl cellulose (HPC), carboxymethyl cellulose (CMC), and hydroxypropyl methyl cellulose (HPMC) (9), crystal nanocellulose (CNC) has also been investigated as a nontoxic gene delivery system. To be used as a vector, needle-like CNC must be modified with a cationic polymer to be able to condense negatively-charged DNA into compact nano-complexes (10). The cationic polymer also decreases the electrostatic repulsion between cell surfaces and DNA, protects plasmid DNA from enzymatic degradation by nucleases, and accelerates cellular transfection. Polyethylenimine, a cationic polymer available in various sizes and shapes, has also been widely used for gene delivery systems alone or complexed with CNC to form nano-complexes. However, polyethylenimine toxicity is the main impediment to its clinical use $(11,12)$.

Increased polyethylenimine molecular weight increases transfection efficiency; however, increased molecular weight also increases cytotoxicity. Most polyethylenimines used for gene delivery are highly branched, mainly because linear polyethylenimine has low DNA-condensing efficiency, despite its lower cytotoxicity (13, 14). This study is the first to investigate whether a high molecular weight $(10 \mathrm{kDa})$ linear polyethylenimine, complexed with $\mathrm{CNC}$ as a biomaterial, could provide a balance of transfection efficiency and biocompatibility. Our results demonstrate that this new nanoparticle, fabricated from surface-modified $\mathrm{CNC}$ with linear PEI, is superior to PEI in both transfection efficiency and subsequent cell viability. Furthermore, this new nanoparticle, at its optimum nanoparticle/plasmid (N/P) ratio, provides transfection efficiency close to, and performs better in cell viability rate, than Lipofectamine. These findings, along with CNC's natural abundancy, showcase it as a promising category of non-viral nanocarriers.

\section{Materials and methods}

PEI10kDa, Propan-1-ol, $\mathrm{NaIO}_{4}$, and $\mathrm{NaBH}_{3} \mathrm{CN}$ were purchased from Sigma Aldrich. FBS, trypsin, penicillin-streptomycin mixture, L-glut, Lipofectamine 2000, and APCcy7 were purchased from Invitrogen Life Science Technologies Company. EZ-Vision dye was obtained from VWR, HEK cells were kindly provided by Dr. Ashkar Lab at McMaster University, and pmaxGFP ${ }^{\mathrm{TM}}$ plasmid was supplied by Lonza Company.

\section{Cellulose nanocrystal preparation}

CNCs were prepared according to the method of Morandi and Vincent $(15,16)$. Briefly, $5 \mathrm{~g}$ of pulp sheet were dispersed in sulfuric acid and incubated at $45^{\circ} \mathrm{C}$ for $35 \mathrm{~min}$. Precipitates were washed 3 times by centrifugation at 15,000 rcf and $10{ }^{\circ} \mathrm{C}$ for $20 \mathrm{~min}$, and then dialyzed for 1 week. The suspensions were filtered via a nylon mesh to remove residual aggregates, lyophilized, and oxidized with sodium periodate. To avoid cellulose super-oxidation, propan-1-ol was added. The mixtures were stirred for 4 days at room temperature in the dark, and the residual periodate was quenched by adding ethylene glycol to the reaction. The oxidized CNC was purified by dialyzing for 2 days against distilled water using a dialysis tube (Mw cut-off 8,000 Da).

\section{CNCP nanoparticle synthesis}

Oxidized CNCs (10 mg) were reacted with $2 \mathrm{mg}$ of PEI10kDa at neutral $\mathrm{pH}$. Then NaBH3CN $(2.5 \mathrm{mg})$ was added followed by mild mechanical stirring for $24 \mathrm{~h}$ at room temperature in the dark. After this reaction, CNCP nanoparticles were purified by centrifugation 2 times at 10,000 rcf for $10 \mathrm{~min}$, and lyophilized. 


\section{Complexation of pmax GFP ${ }^{\mathrm{TM}}$ plasmid with $\mathrm{CNCP}$}

CNCP nanoparticles $(1 \mathrm{mg} / \mathrm{mL})$ in ultrapure water were sonicated for $30 \mathrm{~min}$. Plasmids of pmaxGFPTM $(0.25 \mathrm{nmol}, 3 \mu \mathrm{g})$ were added to CNCP nanoparticle solutions at concentrations of 0.25 to $1 \mathrm{mg}$. Final volumes were adjusted to $1 \mathrm{~mL}$ with PBS. Solutions were stirred at $250 \mathrm{rpm}$ for 30 min and centrifuged at 17,000 $\mathrm{rcf}$ for $10 \mathrm{~min}$. The supernatants were discarded and the pellets containing pmax-CNC-PEI (pCNCP) resuspended in $250 \mu \mathrm{L}$ of $1 \mathrm{X}$ PBS. The free DNA amount in the supernatant was determined using a Nanodrop (GE NanoVue). The DNA amounts bound to CNCP were calculated by subtracting free DNA amounts in the supernatant from total DNA introduced into the sample.

\section{Agarose Gel Electrophoresis Assay}

pCNCP complexes with N/P ratios of $1,5,10$, and 20 were prepared by adding an appropriate volume of $\mathrm{CNCP}$ in $0.15 \mathrm{M} \mathrm{NaCl}$ solution to $500 \mathrm{ng}$ of pmaxGFPTM plasmid. The complexes were incubated at $37{ }^{\circ} \mathrm{C}$ for $30 \mathrm{~min}$ and then electrophoresed on a $1 \%(\mathrm{~W} / \mathrm{V})$ agarose gel containing EZ-Vision dye and with $1 \mathrm{X}$ Trisacetate-EDTA (TAE) running buffer at $90 \mathrm{~V}$ for $60 \mathrm{~min}$. DNA was visualized with a UV lamp using an Alpha Imager imaging system.

\section{Zeta potential and particle size}

The zeta potentials and z-average particle sizes of the freshly-prepared CNCs, CNCPs, and pCNCP complexes were measured using a Malvern Zetasizer Nano instrument. The nanoparticle samples were diluted to $0.1 \mathrm{wt} \%$ in Milli-Q water at $25{ }^{\circ} \mathrm{C}$. The recorded zeta potentials were averages of 12 measurements.

\section{Fourier transform-infrared spectra (FTIR)}

Samples' FTIR spectra were collected with a transmission FTIR spectrometer (Perkin Elmer) using single bounce diamond attenuated total reflectance (ATR) accessory. Solid samples were placed directly on the ATR crystal, and all the measured sample spectra were averaged from 16 scans from 500 to $4,000 \mathrm{~cm}^{-1}$ with a resolution of $4 \mathrm{~cm}^{-1}$.

\section{Atomic force microscopy (AFM) measurement}

Particle morphological properties were investigated by AFM (Nanoscope IIIa MultiMode with
Extender, Veeco Metrology Group, Santa Barbara, CA). Typically, freshly-cleaved mica was precoated with poly-L-lysine, a drop of sample was placed on the treated mica surface for $10 \mathrm{~min}$, the excess sample was rinsed off with milli-Q water, and air-dried before measurements. The experiments were performed in tapping mode with silicon cantilevers (ACTA model, AppNano) using a nominal spring constant of $37 \mathrm{~N} / \mathrm{m}$, a nominal resonant frequency of $300 \mathrm{kHz}$, and a nominal tip radius of $6 \mathrm{~nm}$. Nanoscope analysis of 1.4 was used to process the AFM images.

\section{Cell culture and transfection}

HEK cells, cultured in DMEM medium supplemented with L-glutamine, 10\% (v/v) FBS, 100 units $/ \mathrm{mL}$ penicillin and $100 \mu \mathrm{g} / \mathrm{mL}$ streptomycin were maintained at $37{ }^{\circ} \mathrm{C}$ in a humidified incubator containing $5 \% \mathrm{CO}_{2}$ in air.

\section{In vitro transfection of HEK cells}

To examine green fluorescent protein (GFP) expression and cellular uptake of $\mathrm{pCNCP}$ nanoparticles, HEK cells were seeded at $7 \times 10^{4}$ cells/well in a 24-well plate with $1 \mathrm{~mL}$ DMEM containing $10 \% \mathrm{FBS}$ and incubated at $37^{\circ} \mathrm{C}$ for $24 \mathrm{~h}$. When the cells reached 80-90\% confluency, they were washed with PBS, and then pCNCP nanoparticles were added. At this step $1 \mathrm{ml} /$ well of serum-free culture medium was added. Each well received $2 \mu \mathrm{g}$ of DNA. Naked DNA was used as a negative control. Lipofectamine 2000 was used as positive control following the manufacturer's protocol. The plates were incubated at $37{ }^{\circ} \mathrm{C}$ for $6 \mathrm{~h}$, the cell media was removed and replaced with $1 \mathrm{~mL}$ of complete media, and cultures were incubated for $42 \mathrm{~h}$.

\section{Fluorescence microscopy}

To visualize the pmaxGFPTM transfection, $48 \mathrm{~h}$ after transfection, expression of the enhanced green fluorescent protein in HEK cells was evaluated by fluorescence microscopy (EVOSTM FL Imaging System). The bright-field and overlay images of transfected HEK cells were also prepared to observe the transfected HEK cell morphology. The images were recorded at $4 \mathrm{X}(400 \mu \mathrm{m})$ magnification. 


\section{Flow cytometry}

After transfection, GFP expression and HEK cell viability were determined and calculated by flow cytometry. HEK cells were trypsin zed and plated into 96-well plates at $2 \times 10^{5}$ cells/well and then washed with $200 \mu \mathrm{L}$ of PBS. The plate was then centrifuged at $450 \mathrm{rcf}$ for $5 \mathrm{~min}$ at $4{ }^{\circ} \mathrm{C}$, and the supernatant discarded. Then, $100 \mu \mathrm{L}$ of Fixable Viability Dye (APCcy7) was added to each well and the plate was incubated at $4{ }^{\circ} \mathrm{C}$ for $30 \mathrm{~min}$ in the dark. The plate was centrifuged and washed with $100 \mu \mathrm{L}$ of FACS buffer. The cells were fixed with $1 \%$ paraformaldehyde and the plate was placed at $4{ }^{\circ} \mathrm{C}$ in the dark for $1 \mathrm{~h}$. The plate was centrifuged and cells were resuspended in $100 \mu \mathrm{L}$ of FACS buffer for flow cytometry analysis.

\section{Statistical Analysis}

All experiments were performed in triplicate and data is shown as means \pm standard deviations of these repeats. The Student's t test was used to assess statistical significance and differences were reported as significant for $* p<0.05$, and highly significant for $* * p<0.01$.

\section{Results}

\section{Preparation of $\mathrm{CNC}$ and $\mathrm{CNCP}$}

$\mathrm{CNC}$ was obtained from hydrolysis of pulp sheets using 64\% sulphuric acid (16). As a result of sulphate groups presence, negatively charged surface of CNC was produced as confirmed by dynamic light scattering (DLS) analysis. To covalently conjugate PEI to CNC, oxidized CNC was prepared by sodium periodate. Propan-1-ol was added to the reaction to prevent super oxidation of CNCs. Subsequently, the oxidized $\mathrm{CNC}$ surface was reacted with PEI by adding $\mathrm{NaBH}_{3} \mathrm{CN}$ (17).

\section{Zeta potential and particle size}

The average CNC surface zeta potential and size were $-44.8 \mathrm{mV}$ and $210 \mathrm{~nm}$, respectively (Table 1). By grafting PEI onto the CNC surface, the nanoparticle zeta potential and size increased to $34.2 \mathrm{mv}$ and $324 \mathrm{~nm}$ respectively, resulting from the amine group presence (18).

Table 1. CNC and CNCP nanoparticles were diluted to $0.1 \mathrm{wt} \%$ in Milli-Q water at $25^{\circ} \mathrm{C}$ and their zeta potentials and particle sizes measured on a Malvern Zetasizer Nano instrument.

Zeta potential distribution of $\mathrm{CNC}(\mathrm{mv})$

\begin{tabular}{ccc}
\hline CNC & $-44.8 \pm 1.3$ & $210 \pm 12$ \\
CNCP & $34.2 \pm 0.3$ & $324 \pm 2.12$ \\
\hline
\end{tabular}

Average size of CNC (nm)
The complexation of CNCP nanoparticles with pmaxGFPTM plasmid (pCNCP) in different $\mathrm{N} / \mathrm{P}$ ratios caused the zeta value to increase gradually as the N/P ratio increased from 1 to 20, and this positive charge was not affected at N/P ratios of 20 and above (Fig. 1a). As the N/P ratios increased from 1 to 5 , the pCNCPs decreased in size and then increased as the ratios rose from 5 to 20; however, the size was greatest at an N/P ratio of 1 (Fig. 1b).

\section{Fourier Transform Infrared spectroscopy (FTIR)} FTIR was used to chemically characterize the $\mathrm{CNC}$ before and after surface modification (Fig. 2). A broad band from 3500 to $3200 \mathrm{~cm}^{-1}$ in
CNC spectrum was due to the stretching of the -OH groups (16). The peak at $2892 \mathrm{~cm}^{-1}$ was assigned to $\mathrm{C}-\mathrm{H}$ symmetrical bending and provided the evidence of containing cellulose (19). The peak around $1745 \mathrm{~cm}^{-1}$ was a characteristic of carbonyl stretching at the aldehyde group (20). The peaks at $1430 \mathrm{~cm}^{-1}$ were assigned to $\mathrm{CH}_{2}$ scissoring. The peaks at $1371 \mathrm{~cm}^{-1}$ and $1319 \mathrm{~cm}^{-1}$ were due to $\mathrm{C}-\mathrm{H}$ bending vibrations and $\mathrm{C}-\mathrm{O}$ bonds in aromatic rings of polysaccharide, respectively (21). The peak at $894 \mathrm{~cm}^{-1}$ was a result of rocking vibrations of $\mathrm{CH}_{2}$ groups in the cellulose (22). By using $\mathrm{NaBH}_{3} \mathrm{CN}$ and reductive amination, PEIs were grafted onto oxidized CNC. A peak at $1485 \mathrm{~cm}^{-1}$ was produced in the spectra of 
CNCP, which corresponded to $\mathrm{NH}_{3}{ }^{+}$groups (Fig 2a). The peaks of primary and secondary amines in PEI appeared between 3200 and 3500

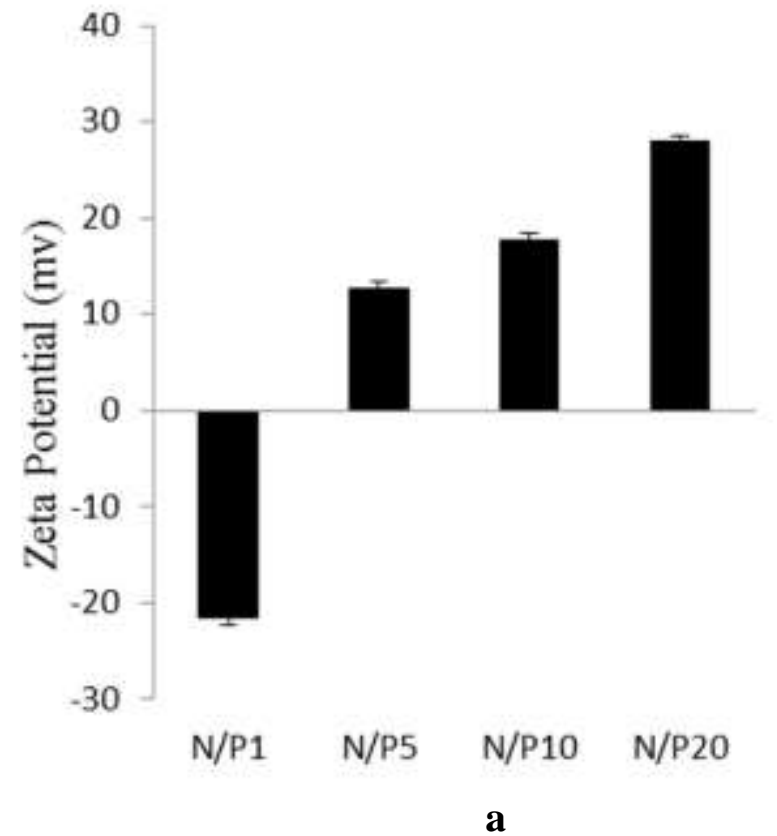

$\mathrm{cm}^{-1}(15)$. Three overlapped peaks belonging to $\mathrm{N}-\mathrm{H}$ bending vibrations were seen between 1600 and $1660 \mathrm{~cm}^{-1}$ (Fig. 2b) (15).

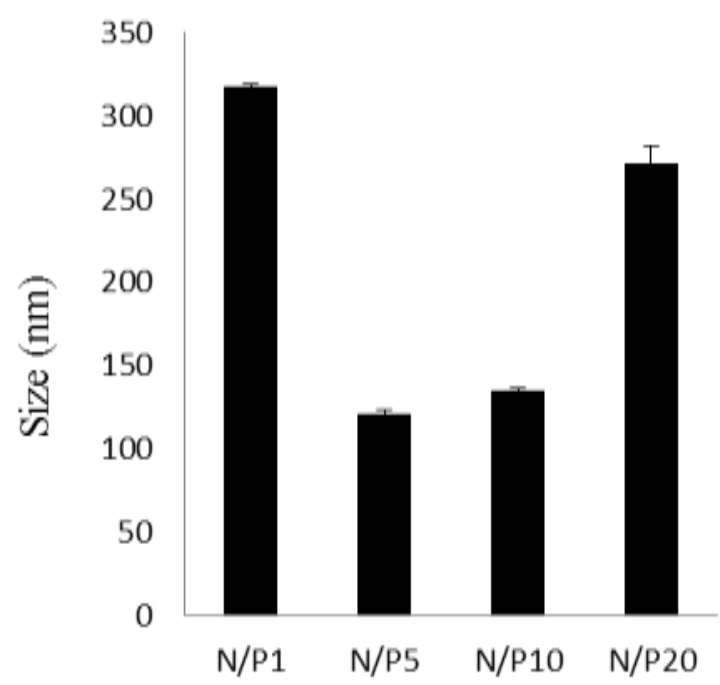

Fig. 1. pmaxGFP ${ }^{\mathrm{TM}}$ plasmids (500 ng) were added to solutions with different CNCP nanoparticle concentrations to form solutions with nanoparticle/plasmid (N/P) ratios of 1, 5, 10, and 20. Samples were stirred at $250 \mathrm{rpm}$ for $30 \mathrm{~min}$, diluted to $0.1 \mathrm{wt} \%$ in Milli-Q water at $25{ }^{\circ} \mathrm{C}$, and their zeta potentials (a) and particle sizes (b) measured on a Malvern Zetasizer Nano instrument. The average of 3 measurements is shown.
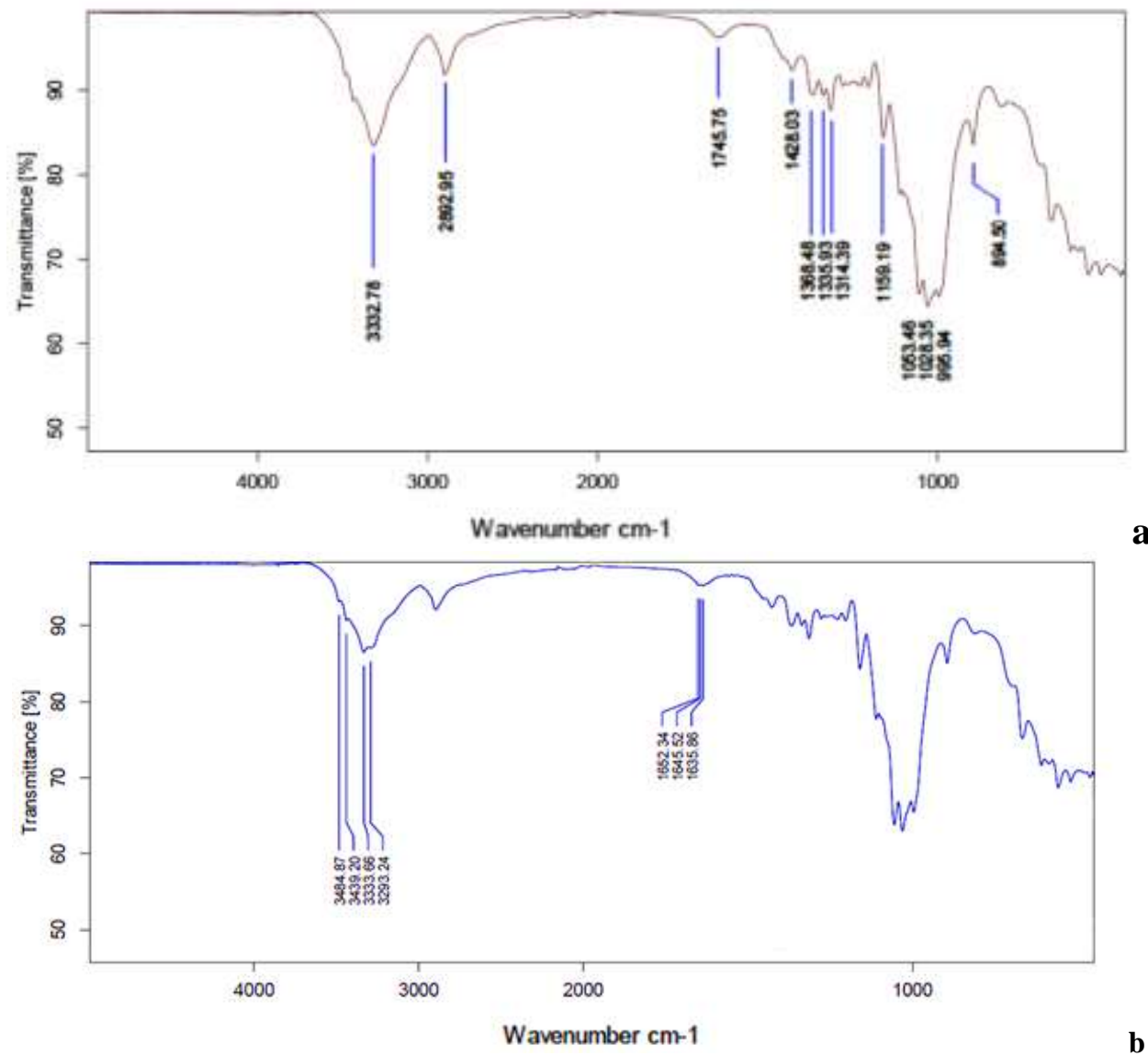

Fig. 2. The FTIR spectra of lyophilised solid samples of (a) CNC and (b) CNCP were measured from 500 to $4,000 \mathrm{~cm}^{-1}$ with a resolution of $4 \mathrm{~cm}^{-1}$. The average of 16 scans is shown. 


\section{AFM}

As determined by AFM imaging, the CNCs

$110-220 \mathrm{~nm}$ and diameters of about $10 \mathrm{~nm}$ contained rod-like particles with lengths of (Fig. 3).

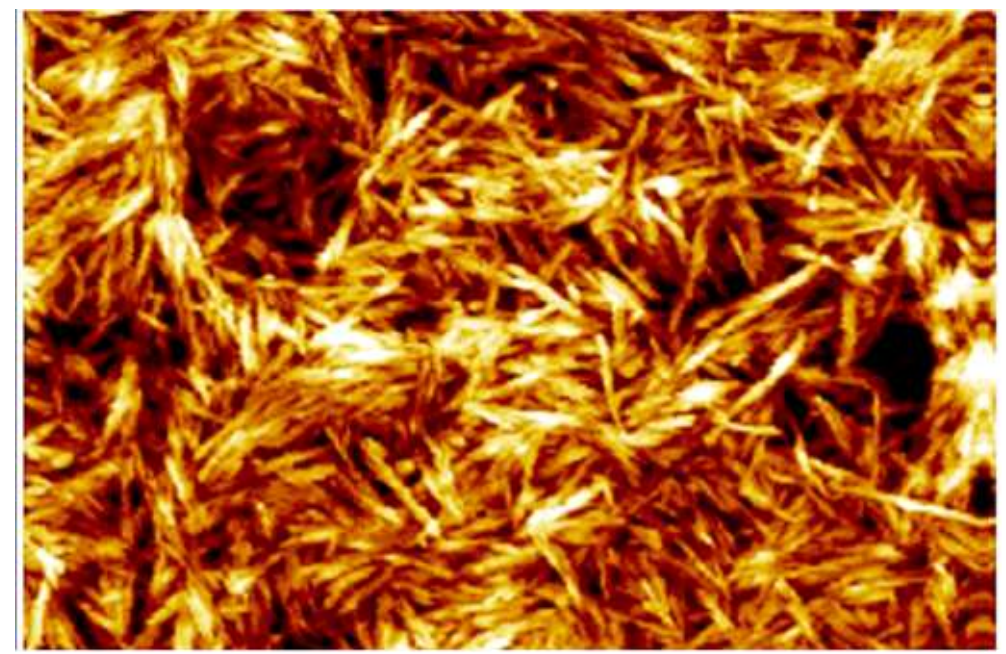

Fig. 3. The morphology of CNCs was visualized by atomic force microscopy (AFM). The AFM was set to tapping mode with silicon cantilevers using a nominal spring constant of $37 \mathrm{~N} / \mathrm{m}$, a nominal resonant frequency of $300 \mathrm{kHz}$, and a nominal tip radius of $6 \mathrm{~nm}$.

\section{Agarose gel electrophoresis}

To perform cellular transfection, DNA condensation capability is a critical prerequisite for any nanocarrier; the DNA must be first condensed by cationic nanoparticles to be suitable for cell entry (23). Therefore, agarose

gel electrophoresis was used to confirm the ability of the CNCP to condense pmaxGFPTM plasmid into particulate structures. The pCNCP complex at N/P ratios of 5 or greater inhibited the DNA migration (Fig. 4).

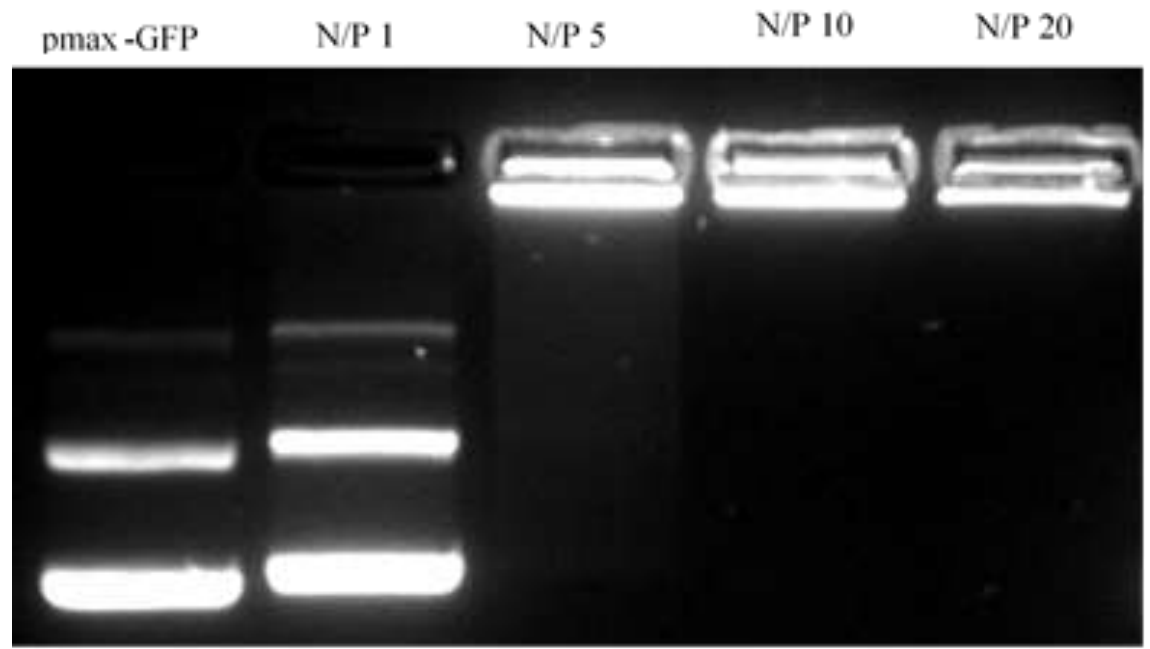

Fig. 4. Electrophoretic mobility of pmaxGFPTM plasmid complexed with CNCP vector at nanoparticle/plasmid (N/P) ratios of 1 , 5,10 , and 20. Samples were electrophoresed in a 1.0\% agarose gel at $90 \mathrm{~V}$ for $60 \mathrm{~min}$. Lane 1: naked pmaxGFPTM plasmid and Lanes 2-5: pCNCP nano-complexes prepared at various N/P ratios. 


\section{In Vitro Gene Transfection Assay}

Pmax-PEI10kDa (pPEI) and pCNCP nanocomplexes were prepared at different $\mathrm{N} / \mathrm{P}$ ratios while maintaining the amounts of pmaxGFPTM plasmid DNA equal to $1 \mu \mathrm{g} /$ well. Subsequently, the transfection efficiency of pCNCP nanoparticles were compared with those of pPEI nanoparticles, naked pmaxGFPTM plasmid, and Lipofectamine 2000.

The transfected HEK cell GFP expression was analyzed by fluorescence microscopy. Fortyeight hours after transfection, no GFP was seen in the naked DNA group (data not shown), while $\mathrm{pCNCP}$ nano-complex groups at various N/P ratios and Lipofectamine 2000 produced green fluorescent cells (Fig. 5). To quantify the transfection efficiency, harvested cells were analyzed by flow cytometry. The transfection efficiency with the pPEI nano-complex increased as the N/P ratio increase from 1 to 20, while with the pCNCP complex, it increased from N/P ratios of 1 to 10 and then decreased at an N/P ratio of 20. Optimal transfection efficiency for pCNCP was obtained at an N/P ratio of 10 , which was significantly greater than the optimal transfection efficiency of the pPEI nano-complex at an N/P ratio of 20. The optimal transfection efficiency of pCNCP was similar to that of Lipofectamine 2000 (Fig. 6a).
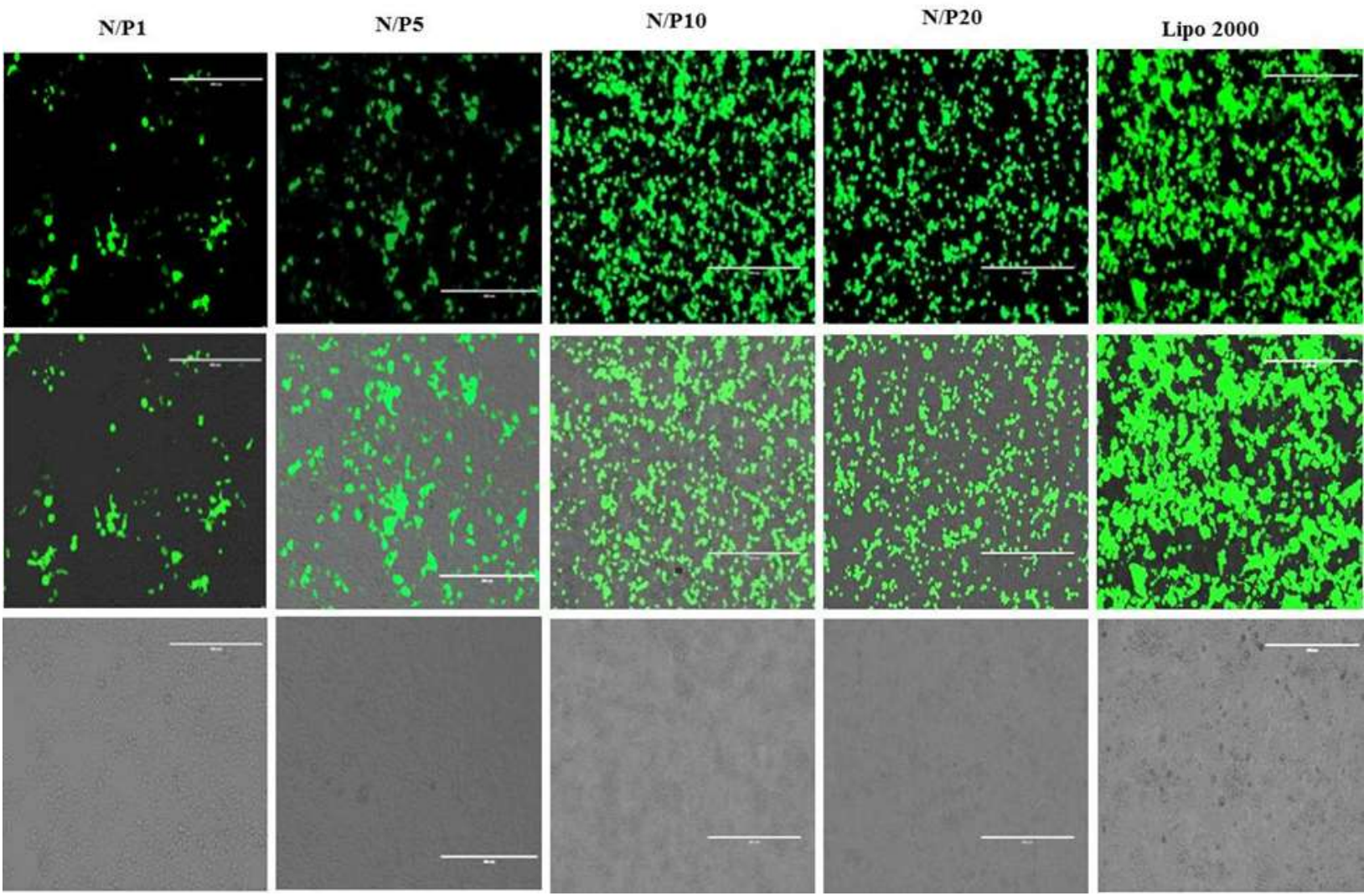

Fig. 5. HEK cells were transfected with $2 \mu \mathrm{g}$ of pmax-GFP ${ }^{\mathrm{TM}}$ plasmid by incubating them for $6 \mathrm{~h}$ with pCNCP nanoparticles at ratios of $1,5,10$, and 20, or Lipofectamine 2000 (ThermoFisher). $42 \mathrm{~h}$ post-transfection cells were imaged using fluorescence microscopy. Fluorescence (top), overlay (middle), and bright-field (bottom) images of green fluorescent protein (GFP) expression in HEK cells are shown.

\section{Cell Viability Assay}

To develop a proper vehicle with high efficacy for gene delivery an important factor to consider is its degree of cell toxicity. The cell viability after treatment with pCNCP and pPEI was evaluated in HEK cells at various
N/P ratios by flow cytometry. We found that with increasing $\mathrm{N} / \mathrm{P}$ ratios the cell viability after treatment with pCNCP and pPEI was decreased; however, the viabilities in the pCNCP nanoparticle-treated groups were 
significantly greater than those treated with the pPEI nanoparticles at all N/P ratios. Of significance, at an N/P ratio of 10 , the pCNCP nanoparticle-treated cells demonstrated significantly greater viability than those treated with Lipofectamine 2000 (Fig. 6b).

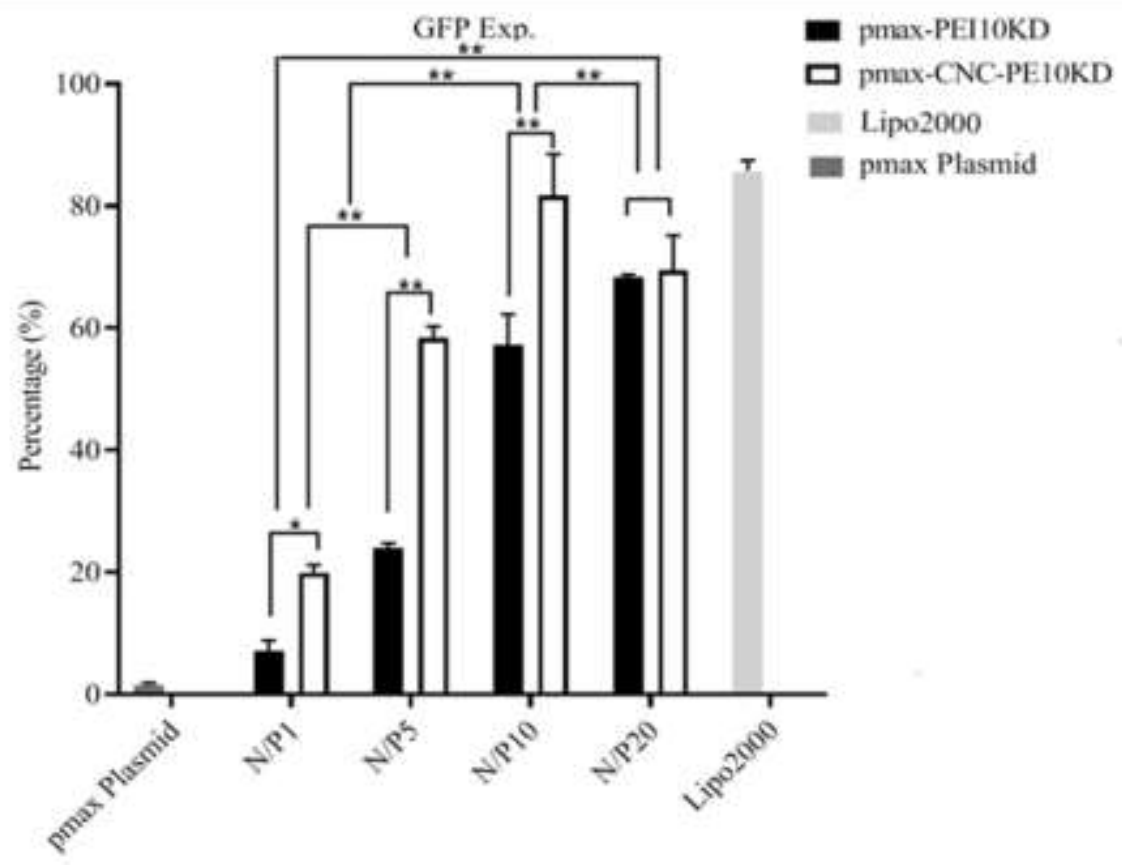

Treatment

$\mathbf{a}$

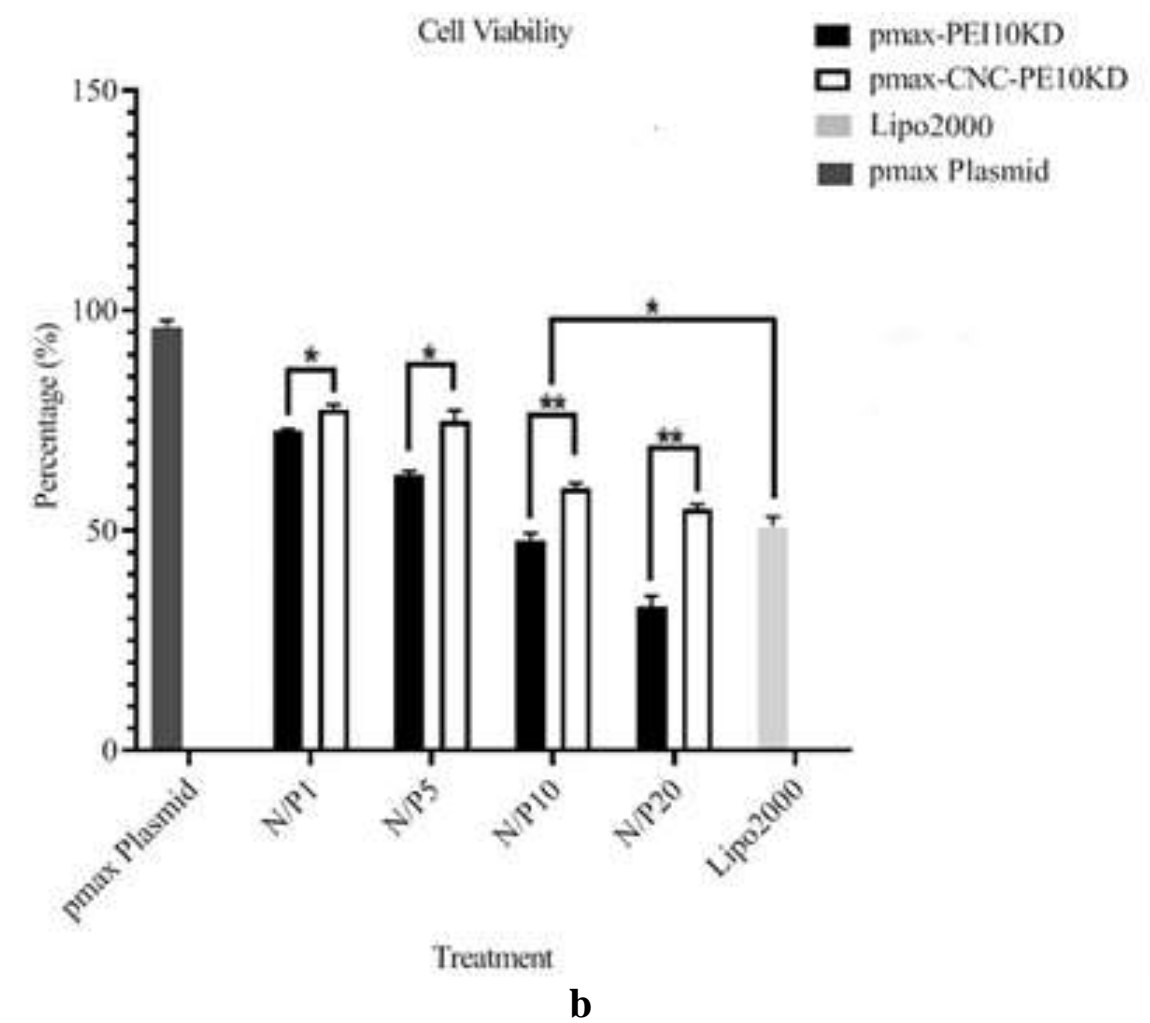

Fig. 6. HEK cells were transfected with $2 \mu \mathrm{g}$ of pmax-GFP ${ }^{\mathrm{TM}}$ plasmid by incubating them for $6 \mathrm{~h}$ with pmax-PEI and pCNCP nanoparticles at ratios of 1, 5, 10, and 20, or Lipofectamine 2000 (ThermoFisher). Gene transfection efficiency (a) and cell viability (b) were quantified via flow cytometry $48 \mathrm{~h}$ after transfection. Significant differences are indicated by stars; **: $\mathrm{p}$-value $<1 \%$, ***: $\mathrm{p}$ value $<0.1 \%, \mathrm{n}=3$. 


\section{Discussion}

Current efforts to generate more efficient vectors than those currently in use for gene delivery in clinical applications have highlighted the importance of biocompatibility and biodegradability in these carriers $(16,24)$. As a natural product, $\mathrm{CNC}$ has been found to be a safe biomaterial for gene delivery (25). In this study we focused on investigating whether prepared nanocarrier from oxidized CNC complexed with linear PEI 10kDa could provide high transfection rate and cell viability in gene delivery.

Physiochemical characteristics of $\mathrm{CNC}$, such as a large surface area and the presence of different functional groups, are key factors that enable CNCs to react with a variety of polymers $(10,23)$. According to the FTIR spectra of oxidized CNC following periodate oxidation a peak of $1745 \mathrm{~cm}^{-1}$ appeared. This peak was related to aldehyde functions and was in equilibrium with hemiacetal groups (26). Therefore, the low signal was likely a result of carbonyl hydration (27). Using the activated aldehyde groups, CNC was complexed with PEI to enable the nanocarrier to condense DNA. The aldehyde peak in the CNCP spectra disappeared after the reductive amination function; however, because of $\mathrm{OH}$ peaks overwhelming primary and secondary amine signals in PEI, the amine signals were masked between 3200 and $3500 \mathrm{~cm}^{-1}$ (20). The aldehyde groups enable CNCs to be modified by reductive amination, in which aldehyde reacts with amine to form imine following their reduction to secondary amine. To obtain a stable structure between aldehyde-modified $\mathrm{CNC}$ and polyethylenimine, an amine reduction of the imine bound group is necessary (28).

Employing polycations to condense polyanionic DNA is an important prerequisite for gene delivery $(7,29)$. Appearance of the peak at $1485 \mathrm{~cm}^{-1}$ was important evidence to confirm PEI was successfully grafted onto the $\mathrm{CNC}$ surface to form a polycationic-CNC nanoparticle (30). These surface-aminated CNCs will allow DNA attachment through the amine groups.

To confirm that the particles were nano-sized, DLS was used to characterize molecular aggregation for oxidized $\mathrm{CNC}$ and $\mathrm{CNCP}$ complexes (31). Due to presence of sulfate groups the $\mathrm{CNC}$ nanoparticles are highly negatively charged. Increasing positive charge on the modified CNCs confirmed successful grafting of PEI onto their surface (18).

Conjugation of pmaxGFPTM plasmid to the CNCP nanoparticles reduced their net charge and increased their size. The CNCP group conferred a higher transfection rate and greater cell viability than the PEI-only group. This significantly greater transfection efficiency of CNCP could be due to the rod shape of the nanoparticle, which has been demonstrated to be more efficient than the spherical shape of PEI-DNA $(20,32)$. On another level, high gene delivery efficiency could be a result of high cell viability due to decreased toxicity of PEI caused by nontoxic CNC (33).

Cationic-modified nanoparticles have been extensively used in gene delivery; in addition to their transfection efficiency it is important to evaluate the essential biocompatibility characteristics of nanoparticles, such as cell toxicity. In nanocarrier construction the N/P ratio plays a crucial role in influencing both transfection efficiency and cytotoxicity $(36,37)$. Optimum N/P ratios in nanoparticles are mainly affected by nanoparticle characteristics including net charge, size, and shape. Various studies have shown that different nanoparticles perform best at different ratios (38-40). In our study the optimum $\mathrm{N} / \mathrm{P}$ ratio of 10 was most probably due to the best balance between the number of amine groups interacting with $\mathrm{CNC}$ to decrease the toxicity of PEI and the number of amine groups available to interact with the greatest possible amount of DNA. In agreement with our results, Ping et al also obtained an optimum transfection rate at an $\mathrm{N} / \mathrm{P}$ ratio of 10 (40).

The higher cell toxicity and lower transfection rates at higher $\mathrm{N} / \mathrm{P}$ ratios could have resulted from an increasing abundance of free CNCPs, which produce high positive surface charges (41). Particles with high positive surface charges could have strong electrostatic interactions with the negative charge of the cell membrane, destabilizing and disrupting it, thus increasing cell endocytosis and death (42). Additionally, higher $\mathrm{N} / \mathrm{P}$ ratios can cause DNA-loaded nanoparticles to be highly stable and decrease DNA release in the 
cytosol (43). At lower N/P ratios of 1 and 5, the greatest possible amount of DNA was not complexed to the nanocarrier due to insufficient CNCP. Low transfection efficiency may also have been due to formation of loose nanocomplexes as a result of lower N/P ratios; in such a situation $\mathrm{CNCP}$ could not efficiently condense pmaxGFPTM plasmid into nano-complexes (23).

Polyethyleneimine, with various molecular weights as a cationic polymer, can complex and condense nucleic acids to facilitate their transport into target cells. However, its toxicity is a serious concern due to its tendency to aggregate and adhere to the cell surface $(44,45)$. To address this issue, in this study, new cellulose-derived nanoparticles were developed for intracellular gene delivery. This novel nanocarrier $\mathrm{CNCP}$ consists of cellulose nanocrystals whose surfaces are covalently modified with PEI, a $10 \mathrm{kDa}$

\section{References}

1. Lin X, Zhao N, Yan P, Hu H, Xu F-J. The shape and size effects of polycation functionalized silica nanoparticles on gene transfection. Acta biomaterialia. 2015;11:381-392.

2. Yin H, Kanasty RL, Eltoukhy AA, Vegas AJ, Dorkin JR, Anderson DG. Non-viral vectors for gene-based therapy. Nature Reviews Genetics. 2014;15(8):541-555.

3. Cotrim AP, Baum BJ. Gene therapy: some history, applications, problems, and prospects. Toxicol pathol. 2008;36(1):97-103.

4. Breen A, Strappe P, Kumar A, O'Brien T, Pandit A. Optimization of a fibrin scaffold for sustained release of an adenoviral gene vector. J Biomed Mater Res A. 2006;78(4):702-8.

5. Lilley CE, Branston RH, Coffin RS. Herpes simplex virus vectors for the nervous system. Curr Gene Ther. 2001;1(4):339-58.

6. Nimesh S, Kumar R, Chandra R. Novel polyallylamine-dextran sulfate-DNA nanoplexes: highly efficient non-viral vector for gene delivery.

Int J Pharm. 2006;320(1-2):143-9.

7. Ahn HH, Lee MS, Cho MH, Shin YN, Lee JH, $\mathrm{Kim} \mathrm{KS}$, et al. DNA/PEI nano-particles for gene delivery of rat bone marrow stem cells. Colloids and cationic polymer. Transfection efficiency and biocompatibility of this CNCP nanoparticle significantly outperformed complexes with PEI or naked pDNA alone.

This study not only introduces an efficient novel nanocarrier but also highlights how $\mathrm{CNC}$, an abundant biomaterial, can be used to develop highly efficacious systems for gene delivery. Further studies focusing on complexing $\mathrm{CNC}$ with other cationic polymers to design more novel nanocarriers and testing their efficiency in in vivo gene delivery would be the next steps to more thoroughly characterize the potential of CNCs in gene transfection.

\section{Acknowledgements}

We are grateful to Professor Ali Ashkar at McMaster University, for kindly providing materials and equipment used in this study.

Surfaces A: Physicochemical and Engineering Aspects. 2008;313-314:116-120.

8. Klemm DB, Heublein B, Fink H-P, A Bohn.

Cellulose: Fascinating Biopolymer and Sustainable Raw Material. Angewandte Chemie International Edition. 2005;44(22):3358-3393.

9. Kamel S, Ali N, Jahangir K, Shah S, El-Gendy

A. Pharmaceutical significance of cellulose: a review. Express Polym Lett. 2008;2(11):758-778.

10.Habibi Y. Key advances in the chemical modification of nanocelluloses. Chem Soc Rev. 2014;43(5):1519-42.

11. Bisht HS, Manickam DS, You Y, Oupicky D. Temperature-controlled properties of DNA complexes with poly (ethylenimine)-g raft-poly ( $\mathrm{N}$ isopropylacrylamide). Biomacromolecules. 2006;7(4):1169-78.

12. Jiang X, Lok MC, Hennink WE. Degradablebrushed pHEMA-pDMAEMA synthesized via ATRP and click chemistry for gene delivery. Bioconjug Chem. 2007;18(6):2077-84.

13. Neu M, Fischer D, Kissel T. Recent advances in rational gene transfer vector design based on poly (ethylene imine) and its derivatives. J Gene Med. 2005;7(8):992-1009. 
14. Bonnet M-E, Erbacher P, Bolcato-Bellemin AL. Systemic delivery of DNA or siRNA mediated by linear polyethylenimine (L-PEI) does not induce an inflammatory response. Pharm Res. 2008;25(12):2972-82.

15. Ntoutoume GMN, Granet R, Mbakidi JP, Brégier F, Léger DY, Fidanzi-Dugas $\mathrm{C}$, et al. Development of curcumin-cyclodextrin/cellulose nanocrystals complexes: new anticancer drug delivery systems. Bioorg Med Chem Lett. 2016;26(3):941-945.

16. Ntoutoume GMN, Grassot V, Brégier $F$, Chabanais J, Petit J-M, Granet R, et al. PEI-cellulose nanocrystal hybrids as efficient siRNA delivery agents - Synthesis, physicochemical characterization and in vitro evaluation. Carbohydr Polym. 2017;164:258-267.

17. Fredon E, Granet R, Zerrouki R, Krausz P, Saulnier L, Thibault J, et al. Hydrophobic films from maize bran hemicelluloses. Carbohydrate polymers. 2002;49(1):1-12.

18. Buchman YK, Lellouche E, Zigdon S, Bechor M, Michaeli S, Lellouche J-P. Silica nanoparticles and polyethyleneimine (PEI)-mediated functionalization: a new method of PEI covalent attachment for siRNA delivery applications. Bioconjug Chem. 2013;24(12):2076-87.

19. Jahan MS, Saeed A, He Z, Ni Y. Jute as raw material for the preparation of microcrystalline cellulose. Cellulose. 2011;18(2):451-459.

20. Dong S, Cho HJ, Lee YW, Roman M. Synthesis and cellular uptake of folic acidconjugated cellulose nanocrystals for cancer targeting. Biomacromolecules. 2014;15(5):1560-7.

21. Sofla MRK, Brown RJ, Tsuzuki T, Rainey TJ. A comparison of cellulose nanocrystals and cellulose nanofibres extracted from bagasse using acid and ball milling methods. Advances in Natural Sciences: Nanoscience and Nanotechnology. 2016;7(3):035004.

22. Sharma H, Carmichael E, Muhamad M, McCall D, Andrews F, Lyons G, et al. Biorefining of perennial ryegrass for the production of nanofibrillated cellulose. RSC Advances. 2012;2(16):6424-6437.

23. Hu H, Yuan W, Liu F-S, Cheng G, Xu F-J, Ma J. Redox-responsive polycation-functionalized cotton cellulose nanocrystals for effective cancer treatment. ACS applied materials \& interfaces. 2015;7(16):8942-51.

24. Habibi Y, Lucia LA, Rojas OJ. Cellulose nanocrystals: chemistry, self-assembly, and applications. Chemical reviews. 2010;110(6):34793500 .

25. Lin N, Dufresne A. Nanocellulose in biomedicine: Current status and future prospect. European Polymer Journal. 2014;59:302-325.

26. Grate JW, Mo K-F, Shin Y, Vasdekis A, Warner MG, Kelly RT, et al. Alexa fluor-labeled fluorescent cellulose nanocrystals for bioimaging solid cellulose in spatially structured microenvironments. Bioconjug chem. 2015;26(3):593-601.

27. Socrates G. Hydration study of acetaldehyde and propionaldehyde. The Journal of Organic Chemistry. 1969;34(10):2958-2961.

28. Sirviö JA, Liimatainen H, Niinimäki J, Hormi O. Sustainable packaging materials based on wood cellulose. RSC advances. 2013;3(37):16590-6.

29. Kim T-H, Seo HW, Han J, Ko KS, Choi JS. Polyethylenimine-grafted polyamidoamine conjugates for gene delivery with high efficiency and low cytotoxicity. Macromolecular Research. 2014;22(7):757-764.

30. Zhao J, Li Q, Zhang X, Xiao M, Zhang W, Lu C. Grafting of polyethylenimine onto cellulose nanofibers for interfacial enhancement in their epoxy nanocomposites. Carbohydr Polym. 2017;157:1419-1425.

31. Cai J, Zhang L, Liu S, Liu Y, Xu X, Chen X, et al. Dynamic self-assembly induced rapid dissolution of cellulose at low temperatures. Macromolecules. 2008;41(23):9345-9351.

32. Gratton SE, Ropp PA, Pohlhaus PD, Luft JC, Madden VJ, Napier ME, et al. The effect of particle design on cellular internalization pathways. Proc Natl Acad Sci U S A. 2008;105(33):11613-8.

33. Mahmoud KA, Mena JA, Male KB, Hrapovic S, Kamen A, Luong JH. Effect of surface charge on the cellular uptake and cytotoxicity of fluorescent labeled cellulose nanocrystals. ACS applied materials \& interfaces. 2010;2(10):2924-2932.

34. Kim U-J, Kuga S, Wada M, Okano T, Kondo T. Periodate oxidation of crystalline cellulose. Biomacromolecules. 2000;1(3):488-492. 
35. Julien S, Chornet E, Overend R. Influence of acid pretreatment $(\mathrm{H} 2 \mathrm{SO} 4, \mathrm{HCl}, \mathrm{HNO} 3)$ on reaction selectivity in the vacuum pyrolysis of cellulose. Journal of Analytical and Applied Pyrolysis. 1993;27(1):25-43.

36. Zhao Q-Q, Chen J-L, Lv T-F, He C-X, Tang G$\mathrm{P}$, Liang $\mathrm{W}-\mathrm{Q}$, et al. N/P ratio significantly influences the transfection efficiency and cytotoxicity of a polyethylenimine/chitosan/DNA complex. Biol Pharm Bull. 2009;32(4):706-10.

37. Zhang X-Q, Wang X-L, Zhang P-C, Liu Z-L, Zhuo R-X, Mao H-Q, et al. Galactosylated ternary DNA/polyphosphoramidate nanoparticles mediate high gene transfection efficiency in hepatocytes. Journal of controlled release. 2005;102(3):749-763. 38. Ge X, Feng J, Chen S, Zhang C, Ouyang Y, Liu $\mathrm{Z}$, et al. Biscarbamate cross-linked low molecular weight Polyethylenimine polycation as an efficient intra-cellular delivery cargo for cancer therapy. Journal of nanobiotechnology. 2014;12(1):13.

39. Sarkar K, Debnath M, Kundu P. Preparation of low toxic fluorescent chitosan-graftpolyethyleneimine copolymer for gene carrier. Carbohydrate polymers. 2013;92(2):2048-2057.

40. Ping Y, Liu CD, Tang GP, Li JS, Li J, Yang
WT, et al. Functionalization of chitosan via atom transfer radical polymerization for gene delivery. Advanced Functional Materials. 2010;20(18):31063116.

41. Fischer D, Li Y, Ahlemeyer B, Krieglstein J, Kissel T. In vitro cytotoxicity testing of polycations: influence of polymer structure on cell viability and hemolysis. Biomaterials. 2003;24(7):1121-31.

42. Cai J, Yue Y, Rui D, Zhang Y, Liu S, Wu C. Effect of chain length on cytotoxicity and endocytosis of cationic polymers. Macromolecules. 2011;44(7):2050-2057.

43. Malamas AS, Gujrati M, Kummitha CM, Xu R, Lu Z-R. Design and evaluation of new $\mathrm{pH}$-sensitive amphiphilic cationic lipids for siRNA delivery. J Control Release. 2013;171(3):296-307.

44. Moghimi SM, Symonds P, Murray JC, Hunter AC, Debska G, Szewczyk A. A two-stage poly (ethylenimine)-mediated cytotoxicity: implications for gene transfer/therapy. Mol Ther. 2005;11(6):990-5.

45. Zintchenko A, Philipp A, Dehshahri A, Wagner E. Simple modifications of branched PEI lead to highly efficient siRNA carriers with low toxicity. Bioconjug Chem. 2008;19(7):1448-55. 